\title{
Electromechanical properties of PZT/P(VDF-TrFE) composite ink printed on a flexible organic substrate
}

T. Siponkoski ${ }^{a}$, M. Nelo, J. Palosaari, J. Peräntie, M. Sobocinski, J. Juuti, H. Jantunen Microelectronics and Materials Physics Lab., P.O. Box 4500, 90014, University of Oulu, Finland

${ }^{\text {a }}$ Corresponding author: tuomo.siponkoski@ee.oulu.fi, tel: +358 50350 3051, fax: +358 85532728

\begin{abstract}
The fabrication and electromechanical properties of composite inks consisting of 30 to 70 vol.\% of piezoceramic PZT powder and piezoelectric co-polymer P(VDF-TrFE) are presented. Samples were stencil-printed on a commercial PET film and printable silver ink was used for the electrodes thus allowing a maximum process temperature of 130 ${ }^{\circ} \mathrm{C}$. The relative permittivity at $1 \mathrm{kHz}$ varied between 33 and 69 depending on poling and composite composition. The highest remanent polarization, up to $4.8 \mu \mathrm{C} / \mathrm{cm}^{2}$, with $34 \mathrm{MV} / \mathrm{m}$ electric field and piezoelectric coefficient $d_{31}$ up to $17 \mathrm{pm} / \mathrm{V}$, was obtained with a 50 vol.\% PZT loading level. The mechanical and electrical results indicate that the developed composite ink enables fully printable and flexible sensor applications with an increased level of integration.
\end{abstract}

Keywords: A. Polymer-matrix composites (PMCs), B. Adhesion, B. Electrical properties, B. Mechanical properties, Printing

\section{Introduction}

In recent years a growing number of electronic devices are designed to be mobile and/or wireless. This has created a need for increased freedom in the selection and integration of components and an interest in the development of lightweight and flexible electronics. As a result there are many alternative composites and fabrication methods 
being studied. In 0-3 ceramic-polymer composites the ceramic particles are embedded as filler material into a polymer matrix in such a way that they are not in contact with each other. The composites' properties are relatively easily controlled by loading and selection of the filler and matrix materials. Furthermore, low temperature processing of printable composites enables the use of a large variety of substrates (including organic materials, e.g. paper and plastics) which is not possible with conventionally sintered ceramics. $^{[1,2]}$

Although there are low processing temperature materials available, only a few components such as passive elements, antennas, LEDs and transistors have been fabricated solely by printing technologies (e.g. ink-jet printing, screen-printing, etc.). ${ }^{[1-}$ 10] Therefore there is still a clear need for fully printed low temperature component structures with functional materials.

Piezoelectric ceramics form one of the most multifunctional material groups in electronics. They are widely used in actuators, sensors and transducers, from igniters to fine precision print heads, fuel injectors, sonars, energy harvesters and echograms. ${ }^{[11-14]}$ The main challenge in piezoelectric composite materials is their low electromechanical performance when compared to that of the bulk ceramics or single crystals. However, piezoelectric printable components offer excellent and low cost large area fabrication opportunities, freedom in substrate material selection (including organic materials) and simplified embedding of components. ${ }^{[1,4-8,15]}$

In many cases either PVDF or P(VDF-TrFE) co-polymer is selected for the polymer matrix of a piezoelectric composite. This is due not only to its crystalline and piezoelectric structure, but also to its easy solution-based processability, low processing temperature, high sensitivity and flexibility with low density. ${ }^{[16-23]}$ In this paper the 
electromechanical properties of piezoelectric PZT/P(VDF-TrFE) inks with 30-70 vol.\% ceramic concentrations are presented. In most piezoelectric or ferroelectric composites studies published, the composite is hot or cold pressed or cast and the structure is not fully printed. In many other printing studies the process temperatures are significantly higher than presented here and/or the substrates are usually inorganic and rigid. ${ }^{[6,21-31]}$ The sample structure presented here is wholly printed, and due to the low processing temperature of $130{ }^{\circ} \mathrm{C}$, an organic flexible PET film is used as a substrate.

\section{Materials and methods}

Four sets of inks with ceramic particle concentrations from 30 to 70 vol.\% of PZ29 (Ferroperm Piezoceramics A/S) were fabricated for printing. The copolymer P(VDFTrFE) 56/44 mol.\% (Solvay-Solexis), having the crystallized ferroelectric phase referred to as $\beta$-phase ${ }^{[23,32]}$, was chosen for the polymer matrix of the ink.

\subsection{Preparation of the PZT-polymer ink composites}

The preparation was started by dissolving the poly(vinylidenefluoridetrifluoroethylene), P(VDF-TrFE), co-polymer powder into dimethylformamide (>99\%, Fluka), which resulted in a clear 20 wt.\% solution for further experiments. In each ink batch produced, $10 \mathrm{~g}$ of PZ29 lead zirconate titanate with an average particle size of 1.3 $\mu \mathrm{m}$ (measured with a Beckman Coulter LS 13320 laser diffraction analyzer) was used and $\mathrm{P}(\mathrm{VDF}-\mathrm{TrFE})$ solution was added in order to prepare solutions containing 30,40 , 50, 60 and 70 vol.\% of PZ29 in dry solids. To each batch, $10 \mathrm{~g}$ of 2-(2-butoxyethoxy)ethylacetate (>99\%, Sigma-Aldrich) and $30 \mathrm{ml}$ acetone was added to decrease the viscosity to a suitable level for milling.

Inks were prepared in a ball mill using nylon milling jars and agate milling balls for 18 hours in order to de-agglomerate the raw material as completely as possible. 
After the milling the viscosity was adjusted for printing by evaporating the acetone and excess of other solvents using a drill mixer and a heating plate. The inks were collected and used for printings usually within a day after preparation.

\subsection{Printing the samples}

A parallel plate capacitor structure pattern (Figure 1) with the electrode dimensions of 10 x $11 \mathrm{~mm}$ was used for the samples. Electrodes were made by screen-printing a low curing temperature silver ink (Dupont 5064H) through a 180 mesh stainless steel screen with $16 \mu \mathrm{m}$ emulsion thickness on a transparent PET film. The silver ink layers were cured for 15 minutes at $130{ }^{\circ} \mathrm{C}$. The piezoelectric ink layers were manually printed on the silver electrodes through a $90 \mu \mathrm{m}$ stencil with a glass doctoring blade followed by settling at room temperature for a minimum of 30 minutes and heat treatment for 30 minutes at $120{ }^{\circ} \mathrm{C}$. Typically, two layers of piezoelectric ink were printed to achieve a layer thick enough for further experiments. The thickness of the piezoelectric layer after drying was defined with a micrometer screw and varied between 30-60 $\mu \mathrm{m}$ depending on the number of layers.

\subsection{Mechanical tests and microstructures}

The adhesion of the cured composite inks on the printed silver ink (DuPont 5064H) was tested by means of a pull-off strength test (Positest AT-A automatic adhesion tester) and a tape peel-test (ASTM D-3359-B cross-hatch test, using an Elcometer 107 X-Hatch kit). An alumina substrate was used in the adhesion tests, in contrast to that used in the electrical measurements. This substrate was chosen because the silver ink used had an 
excellent adhesion to it, thus making sure that the failing point would always be between the composite and silver layers.

For the pull-off tests the samples were fixed to a rigid surface and $\varnothing 20 \mathrm{~mm}$ aluminum dollies were glued to the piezoelectric layers. The pull-off strength tests were carried out on the following day. Three samples of each composite were measured and the average of the results was calculated. The failing point of each sample was between the silver and piezoelectric layers. On tape-peel tests, 3 cross-cut patterns were made to the sample surface with a tool consisting of six parallel blades. Tape was glued on top of the cut pattern and peeled off.

The Young's modulus of each layer was derived by measuring different structures using a tensile stress testing stage (Linkam TST350, Figure 2). Sample width in the tests was $2-3 \mathrm{~mm}$ and length $60-80 \mathrm{~mm}$. The thickness of the steel used to increase the stiffness was $30 \mu \mathrm{m}$, polymer film $98 \mu \mathrm{m}$, and silver electrodes (top and bottom) 12-14 $\mu \mathrm{m}$.

Microstructures of the printed and cured composites where investigated by FESEM (Ultra Plus, Zeiss).

\subsection{Dielectric and electromechanical characterization}

The dielectric properties were measured before and after poling from $1 \mathrm{kHz}$ to $1 \mathrm{MHz}$ with $1 \mathrm{~V}_{\mathrm{pp}}$ signal amplitude using a LCR meter (HP 4284A). In addition, dielectric properties were also determined for bulk samples of PZ29 and P(VDF-TrFE). The ferroelectric properties, hysteresis loops, remanent polarization, coercive electric field and leakage current were measured up to an electric field of $34 \mathrm{MV} / \mathrm{m}$ with a high voltage ferroelectric tester (Radiant RT6000HVS). The samples were poled in a 15 $\mathrm{MV} / \mathrm{m}$ electric field at room temperature for 1 hour. The piezoelectric coefficient $d_{31}$ 
was measured from cantilever shaped samples by using a Laser Doppler-vibrometer (OFV-552 measuring probe, Polytech GmbH, Waldbronn). ${ }^{[33]}$

\section{Results and discussion}

The printability of the samples differed depending on the concentrations of PZT. The samples printed with $30 \mathrm{vol} . \%$ of PZT in ink were the easiest to fabricate and they had the smoothest surfaces. Inks which had 60-70 vol.\% of PZT were difficult to print. The samples made with these inks had high porosity, agglomeration of ceramic particles and percolation. Thus these samples had a very low electric breakdown voltage compared to those with lower loading levels and they were discarded from the ferroelectric and piezoelectric measurements.

\subsection{Physical characterization of the cured ink}

Figure 3, FESEM backscattering images from the surface of the cured composites with filler loadings from 30 to 60 vol.\%, shows that the PZT particles (white and gray areas) were scattered inside the P(VDF-TrFE) phase (partly transparent areas). It can be seen that the agglomeration of the ceramic particles slightly increased with the loading level. In addition, the amount of pores in the 60 vol. $\%$ sample (marked with arrows) was more evident. At the same time, the percolation level of the ceramic particles was also high. This percolation effect and increasing porosity in composites having more than 50 vol.\% of ceramic particles has also been reported in some other PVDF composite studies $^{[33-36]}$.

Figures 4-5 show the measured adhesion of the cured inks. The pull-off strength of the samples (Figure 4) increased with the increasing amount of PZT loading. The maximum value of 3.3 MPa was reached with 50 vol.\% loading after which it decreased rapidly. This indicates that there are structural problems in samples containing 60 vol.\% 
or more of PZT. Figure 5 shows a typical cross-hatch cut pattern for all cured composite inks after the peeling test, with no chips removed by peeling. Thus all cured composites achieved a 5B result on the ASTM standard. This test showed that even with the highest ceramic loading levels the adhesion remained high.

\subsubsection{Dielectric properties before poling}

In Figure 6 the dielectric properties of the 30-70 vol.\% composite samples at $1 \mathrm{kHz}$, $100 \mathrm{kHz}$ and $1 \mathrm{MHz}$ are reported. The relative permittivity of the samples increased with the loading level until it reached 50 vol.\% at all frequencies. For example, at $1 \mathrm{kHz}$ the relative permittivity values were 37 to 69 and $\tan \delta 0.047$ to 0.058 when the loading levels were 30 and 50 vol.\%, respectively. The largest change in permittivity was between the 30 and 40 vol.\% samples. These results are in a good agreement with the PVDF-PZT composite ink study by Dietze et al. ${ }^{[24]}$. The relative permittivity of the samples was approximately 10-30\% higher than the values reported for many other binary composites with a PVDF matrix ${ }^{[28,29,34,36-40]}$. Besides the differences in ink and sample fabrication, this is probably due to slightly different ceramic fillers being used in these studies. The permittivity collapsed when the amount of PZT in the composite was increased to 60 and 70 vol.\%. The decrease in permittivity is caused by the pores which are clearly visible in the FESEM picture with high loading levels (Figure 3). In addition, the pores are expected to decrease the contact area between the composite and the electrodes, thus also decreasing the estimated permittivity value ${ }^{[24]}$.

\subsubsection{Calculations of permittivity by mixing equations}

Permittivity of a composite with different loadings can be evaluated by using various mixing formulas such as Lichtnecker, Maxwell-Wagner or Bruggeman equations, series mixing and Effective Medium Theory (EMT) ${ }^{[41]}$. In Figure 7a the measured 
permittivity of the samples is compared with values calculated with modified Lichtnecker (open squares) and the Effective Medium Theory (open diamonds) ${ }^{[41-42]}$. The dielectric properties of bulk PZ29 (filler) and PVDF-TrFE copolymer (matrix) used in calculations are shown in Table 1.

Modified Lichtnecker equation:

$\log \varepsilon_{e f f}=\log \varepsilon_{m}+f(1-n) \log \left(\frac{\varepsilon_{i}}{\varepsilon_{m}}\right)$

Effective medium theory (EMT):

$\varepsilon_{e f f}=\varepsilon_{m}\left[1+\frac{f\left(\varepsilon_{i}-\varepsilon_{m}\right)}{\varepsilon_{m}+n(1-f)\left(\varepsilon_{i}-\varepsilon_{m}\right)}\right]$

where $\varepsilon_{\mathrm{eff}}, \varepsilon_{\mathrm{m}}$ and $\varepsilon_{\mathrm{i}}$ are the permittivity of composite, matrix and filler materials, respectively, $f$ is the volume fraction of the ceramic and $n$ is a fitting parameter.

The results of the equations match very well to the measured values at lower loading levels. However when the amount of PZT in the composite exceeds 50 vol.\%, the measured values start to diverge significantly from the calculated ones.

Dielectric losses can also be calculated with the mixing formulas, for example by using a commonly known parallel mixing equation ${ }^{[42]}$ :

$\tan \delta_{e f f}=f_{m} \tan \delta_{m}+f_{i} \tan \delta_{i}$

where $\tan \delta_{\text {eff }}, \tan \delta_{\mathrm{m}}$ and $\tan \delta_{\mathrm{i}}$ are the loss tangent of the composite, matrix and the filler, and $f_{m}$ and $f_{i}$ are the volume fraction of the matrix and the filler, respectively. In Figure $7 \mathrm{~b}$ the measured effective loss tangent of the samples is compared with calculated values. The results show that the presented mixing equations can be safely used to predict the dielectric properties of the research composites up to $\sim 50$ vol. $\%$ loading in the frequency range from $1 \mathrm{kHz}$ to $1 \mathrm{MHz}$. At higher loading levels the deviation from 
the calculated values support the earlier observations on percolation and other nonidealities found in the composite microstructure.

\subsubsection{Dielectric properties after poling}

The dielectric properties for composites with 30 to 50 vol.\% loading levels were measured again after the poling (Table 2). The higher the PZT loading used in the composite, the higher was the decrease of relative permittivity observed after poling. This decrease in relative permittivity of the composites after the poling followed the known behavior of PVDF-TrFE copolymer ${ }^{[29,40,43]}$.

\subsection{Remanent polarization of the composites}

The remanent polarization of the samples up to $34 \mathrm{MV} / \mathrm{m}$ is presented in the Figure 8 . Similarly as with the relative permittivity, the values increased with the composites' filler concentration and the largest change was observed between 30 and 40 vol.\% samples. The differences between 40 and 50 vol.\% samples remanent polarization were relatively low and started to diverge more clearly above a $22 \mathrm{MV} / \mathrm{m}$ measurement field. The maximum remanent polarization $P_{r}\left(4.8 \mu \mathrm{C} / \mathrm{cm}^{2}\right)$ was obtained for the samples with 50 vol.\% of PZT.

All samples were found to withstand fields of $15 \mathrm{MV} / \mathrm{m}$ without breakdown and consequently this value was selected as the poling field. However it is likely that the composite with 40 vol.\% of PZT could have been polarized in a higher electric field than the others, thus probably attaining a higher piezoelectric performance.

\subsection{Piezoelectric properties of the composites}


In order to measure the piezoelectric properties of the composites, the Young's modulus of the substrate and samples were first evaluated by measuring the strain, $\varepsilon$, and stress, $\sigma$, when stretching rectangular shaped samples:

$$
\begin{gathered}
\varepsilon=\frac{\Delta L}{L} \\
\sigma=\frac{F}{A}
\end{gathered}
$$

where $L$ is the length, $\Delta L$ the change in samples length, $F$ the applied tension, and $A$ is the area normal to the tension.

The Young's modulus can be calculated by:

$E=\frac{\sigma}{\varepsilon}$

The Young's modulus values of the cured piezoelectric ink, polymer film and steel foil $(30 \mu \mathrm{m})$ calculated from the measurements were 1.3, 5.5 and 195 GPa respectively.

Using a simply supported unimorph cantilever, the piezoelectric coefficient $d_{31}$ can be calculated by combining the elastic properties of the layers and the cantilever's mechanical response to the electrical input ${ }^{[33]}$ :

$\delta_{0}=\frac{3 L^{2}}{t_{p}^{2}} \times \frac{A B(1+B)}{A^{2} \times B^{4}+2 A\left(2 B+3 B^{2}+2 B^{3}\right)+1} \times d_{31} V_{0}$

where $L$ is the tip length, $t_{p}$ is the tip thickness, $V_{0}$ is the input voltage and $\delta_{0}$ is the tip deflection, and parameters $A$ and $B$ are defined as:

$A=\frac{E_{m}}{E_{p}} \quad B=\frac{t_{m}}{t_{p}}$

where $E$ is Young's modulus, $t$ is layer thickness and subscription $m$ corresponds to the substrate layer (steel and polymer film) and $p$ to the piezoelectric layer.

All the composites having 30-50 vol.\% concentrations of PZT particles showed a mechanical response when an input voltage was applied to the samples. The piezoelectric coefficient of the composites, calculated using the results of mechanical 
and electromechanical measurements, are presented in Table 2. The coefficient was enhanced with increasing amounts of PZT, as expected. Here the change between 40 vol.\% and 50 vol.\% of PZT is relatively large. An effective transverse piezoelectric coefficient $\left(d_{31}\right)$ of $17 \mathrm{pm} / \mathrm{V}$ (around $7 \%$ of the bulk PZ29 ceramic) was measured from the cured ink having 50 vol.\% of PZT. ${ }^{[44]}$ This composition shows comparable and even higher piezoelectric coefficients than so far reported for oriented P(VDF-TrFE) copolymer films or similar printed composites. ${ }^{[9,17,24,45]}$ Therefore the developed composite ink can be used in fully printable and flexible sensor applications with increased level of integration.

\section{Conclusions}

Piezoelectric composite inks were developed using commercially available piezoelectric ceramic PZ29 and P(VDF-TrFE) copolymer powders. The ceramic loading in the composite was varied between $30-70$ vol.\%. The printed samples were successfully fabricated on a commercial flexible organic film and cured at low temperatures (130 $\left.{ }^{\circ} \mathrm{C}\right)$. Cured inks having less than 50 vol.\% ceramic particles showed good quality in microscopic and mechanical analysis. The relative permittivity at $1 \mathrm{kHz}$ increased from 37 to 69 as a function of ceramic loading level up to 50 vol.\%. Samples with 60 and 70 vol.\% loadings were discarded from the high electric field measurements due to increased composite porosity and agglomeration of the ceramic particles. Based on the observations from structural and electrical investigations, it can be stated that the most appropriate ceramic loading for these composite inks was between 40 and 50 vol.\%. The highest $\operatorname{Pr}\left(4.8 \mu \mathrm{C} / \mathrm{cm}^{2}\right)$ in a $34 \mathrm{MV} / \mathrm{m}$ electric field and the highest $d_{31}(17 \mathrm{pm} / \mathrm{V})$ were achieved with a composite having 50 vol.\% of PZT. However, the performance of the sample with 40 vol.\% of PZT could be directly improved in the future by using 
higher electric fields in poling. Similarly, the whole poling process should be optimized in terms of temperature and poling field (direction and strength) to achieve the optimal performance of these composites. Even at this stage the obtained research results are highly promising.

\section{Acknowledgements}

The authors acknowledge Tekes funded project "Innoinks" 906/31/2010 and its copartners: Jozef Stefan Institute (SLO), ITME (POL), Sachtleben Pigments Oy (FIN), Pulse Finland Oy (FIN) and NOF Corporation (JAP) and also the Riitta ja Jorma J. Takanen foundation and Infotech Oulu Doctoral Program for supporting this study.

\section{References}

1. Subramanian V., Josephine B., De La Fuente Vornbrock A., et al., Printed Electronics For Low-Cost Electronic Systems: Technology Status and Application Development, ESSDERC 2008 - Proc. of the 38th European Solid-State Device Research Conference, 2008, 4681785, pp. 17-24.

2. Das R. N., Lin H. T., Lauffer J.M., et al., Printable electronics: towards materials development and device fabrication, Circuit World 2011, 37 (1), pp. 38-45.

3. Parashkov R., Becker E., Riedl T., et al., Large Area Electronics Using Printing Methods, Proc. of the IEEE 2005, 93 (7), pp 1321-1329.

4. Oprea A, Bârsan N., Weimar U., et al., Capacitive humidity sensors on flexible RFID labels, Sensors and Actuators, B: Chemical 2008, 87(2), pp. 226-232.

5. Briand D., Oprea A., Courbat J., et al., Making environmental sensors on plastic foil, Materials Today 2011, 14 (9), pp. 416-423.

6. Arshak K.I., McDonagh D, Durcan M.A., Development of new capacitive strain sensors based on thick film polymer and cermet technologies, Sensors and Actuators, A: Physical 2000, 79 (2), pp. $102-114$. 
7. Rida A., Yang L., Vyas, R., et al. Conductive Inkjet-Printed Antennas on Flexible Low-Cost PaperBased Substrates for RFID and WSN Applications, IEEE Antennas and Propagation Magazine 2009, 51 (3), pp. 13-23.

8. Virtanen J., Ukkonen L, Björninen T., et al., Inkjet-Printed Humidity Sensor for Passive UHF RFID Systems, IEEE Trans. on Instrumentation and Measurement 2011, 60 (8), 5759086, pp. 2768-2777.

9. Zirkl M., Sawatdee A, et al., An All-Printed Ferroelectric Active Matrix Sensor Network Based on Only Five Functional Materials Forming a Touchless Control Interface, Advanced Materials 2011, 23 (18), pp. 2069-2074.

10. Kim S.H., Hong K., Xie W., et al., Electrolyte-Gated Transistors for Organic and Printed Electronics, Advanced Materials 2013, 25 (13), pp. 1822-1846.

11. Safari A., Akdogan E. K., Piezoelectric and Acoustic materials for Transducer Applications, Springer 2008, New York.

12. Jaffe B., Cook W.R., Jaffe H., Piezoelectric ceramic, Academic Press 1971, London.

13. Moulson A.J., Electroceramics, $2^{\text {nd }}$ Edititon, Chapman and Hall 2003, London.

14. Palosaari J., Leinonen M., Hannu J., Juuti J., Jantunen H., Energy harvesting with a cymbal type piezoelectric transducer from low frequency compression, Journal of Electroceramics 2012, 28 (4) pp. 214-219.

15. Hübler A. C., Bellmann M., Schmidt G.C., et al., Fully mass printed loudspeakers on paper, Organic Electronics: physics, materials, applications 2012, 13 (11), pp. 2290-2295.

16. Tajitsu Y., Chiba A., Crystalline phase transition in the copolymer of vinylidenefluoride and trifluoroethylene, Applied Physics Letters 1980, 36 (4), pp. 286-288.

17. Koga K., Ohigashi H., Piezoelectricity and related properties of vinylidene fluoride and trifluoroethylene copolymers, Journal of Applied Physics 1986, 59 (6), pp. 2142-2150.

18. Z-Y. Cheng, Bharti V., Xu T.-B., et al., Electrostrictive poly(vinylidene fluoride-trifluoroethylene) copolymers, Sensors and Actuators, A: Physical 2001, 90 (1-2), pp. 138-147.

19. Chen Q., Natale D., Neese B., et al., Piezoelectric Polymers Actuators for Precise Shape Control of Large Scale Space Antennas, Proceedings of SPIE - The International Society for Optical Engineering 2007, 6524, 65241P. 
20. Zhang, D.-Q., Wang D.-W., Yuan J., et al., Structural and Electrical Properties of PZT/PVDF Piezoelectric Nanocomposites Prepared by Cold-Press and Hot-Press Routes, Chinese Physics Letters 2008, 25 (12), pp. 4410-4413.

21. Hu Z., Tian M., Nysten B., et al., Regular arrays of highly ordered ferroelectric polymer nanostructures for non-volatile low-voltage memories, Nature Materials 2009, 8 (1), pp. 62-67.

22. Tomer V., Manias E., Randall C.A., High field properties and energy storage in nanocomposite dielectrics of poly(vinylidene fluoride-hexafluoropropylene), J. of Applied Physics 2011, 110 (4), 044107 .

23. Canavese, G., Stassi, S., Cauda, V., et al., Different Scale Confinements of PVDF-TrFE as Functional Material of Piezoelectric Devices, IEEE Sensors Journal 2013, 13 (6), art. no. 6468056, pp. 2237-2244.

24. Dietze M., Es-Souni M., Structural and functional properties of screen-printed PZT-PVDF-TrFE composites, Sensors and Actuators, A: Physical 2008, 143 (2), pp. 329-334.

25. Machida O., Shimofuku A., Tashiro R., et al, Fabrication of Lead Zirconate Titanate Films by Inkjet Printing, Japanese Journal of Applied Physics 2012, 51 (9 PART 2), 09LA11.

26. Gentil S.,Damjanovic D., Setter N.,Development of relaxor ferroelectric materials for screenprinting on alumina and silicon substrates, Journal of the European Ceramic Society 2005, 25 (12 SPEC. ISS.), pp. 2125-2128.

27. Divya P. V., Ambika D., Krishnan D., et al., Fabrication and tunable dielectric properties of $\left(\mathrm{Ba}_{0.7}\right.$ $\left.\mathrm{Sr}_{0.3}\right) \mathrm{TiO}_{3}$-glass-based thick-film capacitors, International Journal of Applied Ceramic Technology 2009, 6 (2), pp. 231-235.

28. Zhang, L., Wu, P., Li, Y., Cheng, Z.-Y., et al., Preparation process and dielectric properties of $\mathrm{Ba}_{0.5} \mathrm{Sr}_{0.5} \mathrm{TiO}_{3}-\mathrm{P}(\mathrm{VDF}-\mathrm{CTFE})$ nanocomposites, Composites Part B: Engineering 2014, 56, pp. 284289.

29. Lam K.-H., Wang X., Chan H.L-W., Piezoelectric and pyroelectric properties of $\left(\mathrm{Bi}_{0.5} \mathrm{Na}_{0.5}\right)_{0.94} \mathrm{Ba}_{0.06} \mathrm{TiO}_{3} / \mathrm{P}(\mathrm{VDF}-\mathrm{TrFE})$ 0-3 composites, Composites Part A: Applied Science and Manufacturing 2005, 36 (11), pp. 1595-1599.

30. Thongsanitgarn P., Watcharapasorn A., Jiansirisomboon S., Electrical and mechanical properties of PZT/PVDF 0-3 composites, Surface Review and Letters 2010, 17 (1), pp. 1-7.

31. Sakamoto W. K., De Campos Fuzari Jr G., Zaghete M. A., et al., Lead Titanate-Based Nanocomposite: Fabrication, Characterization and Application and Energy Conversion Evaluation, 
Ferroelectrics - Material Aspects 2011, Dr. Mickaël Lallart (Ed.), InTech, ISBN: 978-953-307-3323.

32. Heremans P., Gelinck G.H., Müller R., et al., Polymer and Organic Nonvolatile Memory Devices, Chemistry of Materials 2011, 23 (3), pp. 341-358.

33. Wang Q.-M., Du X.-H., Xu B, et al., Electromechanical Coupling and Output Efficiency of Piezoelectric Bending Actuators, IEEE Transactions on Ultrasonics, Ferroelectrics, and Frequency Control 1999, 46 (3), pp. 638-646.

34. Dang Z.-M., Shen Y., Nan C.-W., Dielectric behavior of three-phase percolative Ni$\mathrm{BaTiO}_{3}$ /polyvinylidene fluoride composites, Applied Physics Letters 2002, 81 (25), pp. 4814-4816.

35. Ploss B., Ng W.-Y., Chan H.1.-W., et al., Poling study of PZT/P(VDF-TrFE) composites, Composites Science and Technology 2001, 61 (7), pp. 957-962.

36. Yang W., Yu S., Sun R., et al., Nano- and microsize effect of CCTO fillers on the dielectric behavior of CCTO/PVDF composites, Acta Materialia 2011, 59 (14), pp. 5593-5602.

37. Xu R., Chen W., Zhou J., et al., Dielectric and Piezoelectric Properties of 0-3 PZT/PVDF Composite Doped with Polyaniline, Journal Wuhan University of Technology, Materials Science Edition 2006, 21 (1), pp. 84-87.

38. Dietze M., Krause J., Solterbeck C.-H., et al., Thick film polymer-ceramic composites for pyroelectric applications, Journal of Applied Physics 2007, 101 (5), 054113.

39. Guan X., Zhang Y.,Li H., et al., PZT/PVDF composites doped with carbon nanotubes, Sensors and Actuators, A: Physical 2013, 194, pp. 228-231.

40. Lam K.H., Chan H.L.W., Piezoelectric and pyroelectric properties of 65PMN-35PT/P(VDF-TrFE) of 0-3 composites, Composites Science and Technology 2005, 65 (7-8), pp. 1107-1111.

41. Sebastian M.T., Jantunen H., Polymer-Ceramic Composites of 0-3 Connectivity for Circuits in Electronics: A Review, International Journal of Applied Ceramic Technology 2010, 7 (4), pp. 415434.

42. Tuhkala M., Juuti J., Jantunen H., Method to characterize dielectric properties of powdery substances, Journal of Applied Physics 2013, 114 (1), 014108.

43. PlossB., Ploss B., Dielectric nonlinearity of PVDF-TrFE copolymer, Polymer 2000, 41 (16), pp. $6087-6093$. 
44. Ferroperm-Piezo, Ferroperm Piezoceramics catalogue, 2003, p. 13, URL: http://www.ferropermpiezo.com/, 24.4.2014.

45. Piezotech S.A.S., Piezoelectric Films Technical Information, Piezoelectric films leaflet, p. 11, URL:http://www.piezotech.fr/image/documents/22-31-32-33-piezotech-piezoelectric-filmsleaflet.pdf, 24.4.2014. 


\section{Figures}

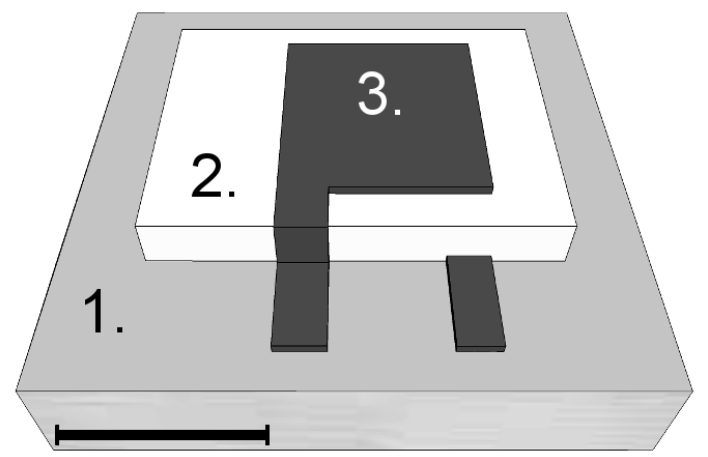

Figure 1.Schematic presentation of the printed structure. Layers: $1=$ polymer substrate, $2=$ printed composite, $3=$ printed electrodes. Scale bar $=1 \mathrm{~cm}$.

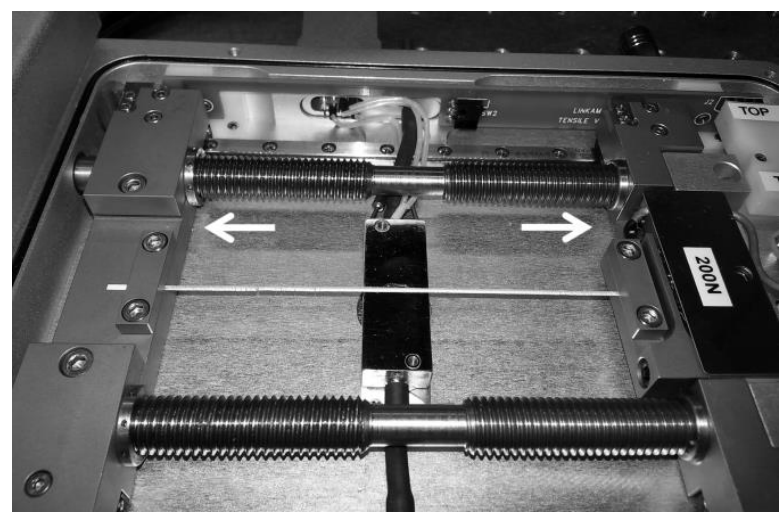

Figure 2. Linkam tensile stress testing stage TST350. Printed sample in the center fixed between the jaws. Arrows are showing the direction of the tension in the measurement. 

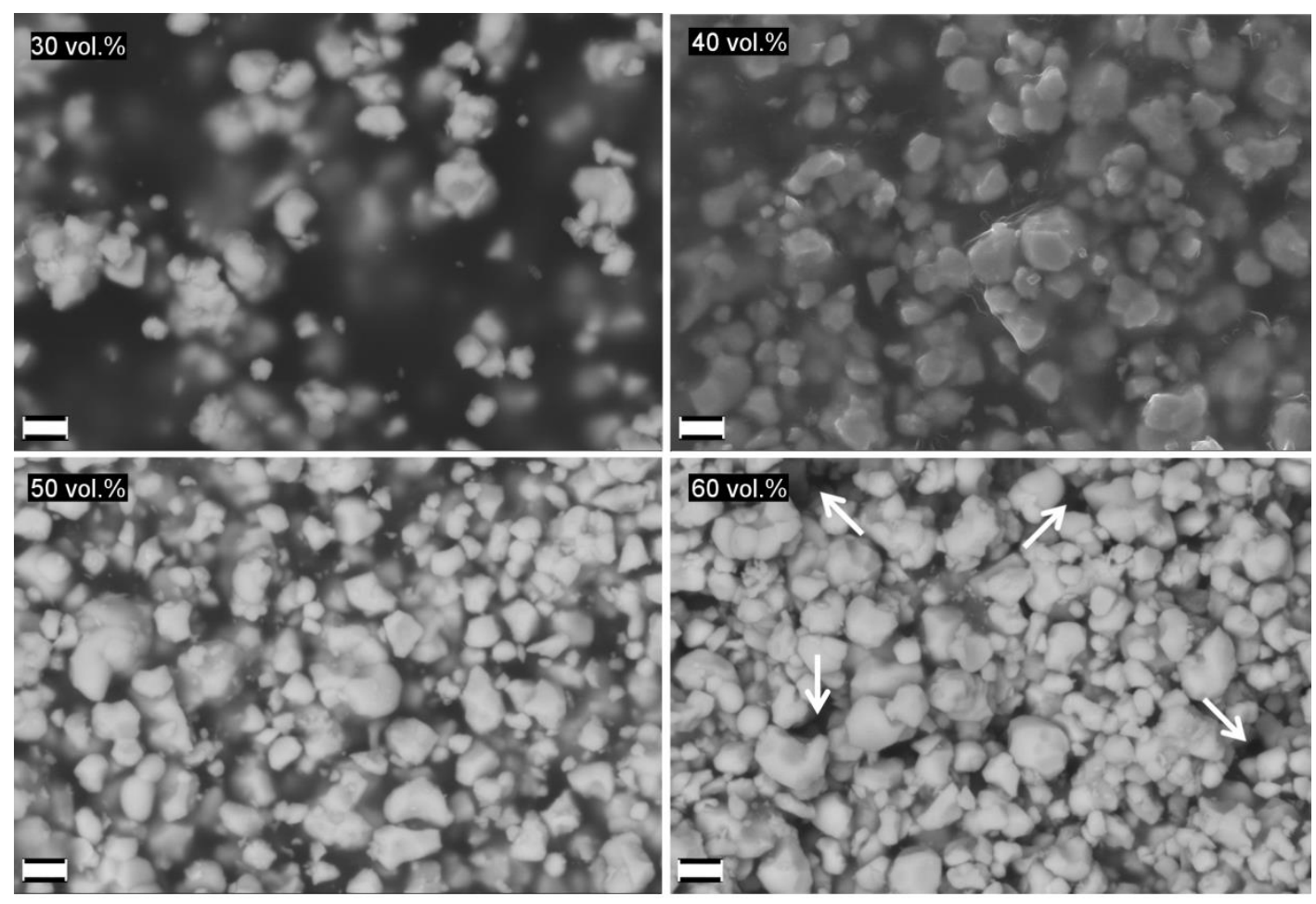

Figure 3. FESEM backscattering images of the surfaces of printed and cured samples.

Magnification $=20000$, scale bar $=1 \mu \mathrm{m}$.

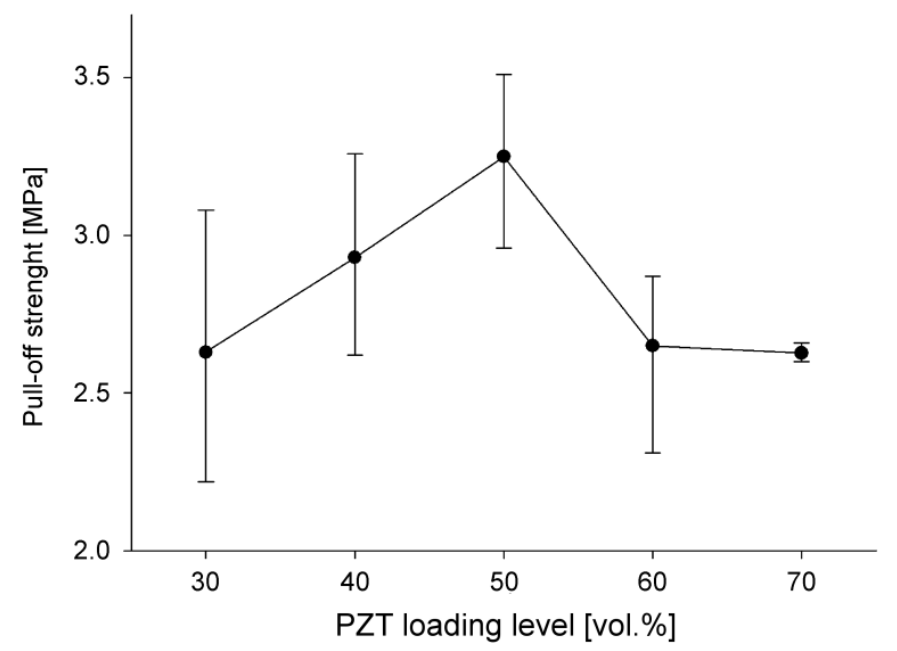

Figure 4. Pull-off strength as a function of PZT loading level of the composite. Error bars indicate variation within the composite composition. 


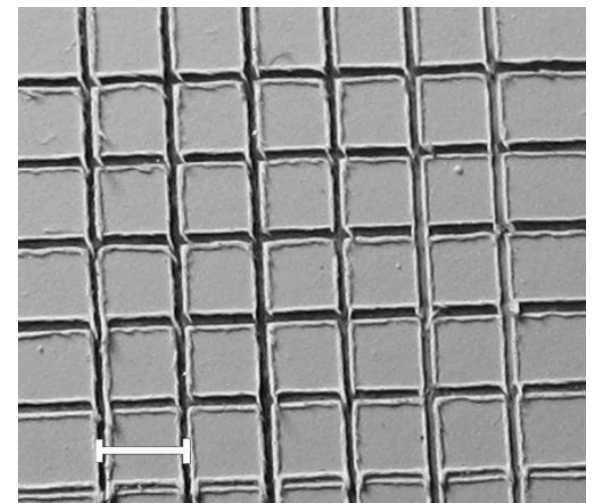

Figure 5. Typical surface of a composite sample after ASTM D-3359-B cross-hatch test. Scale bar $=1 \mathrm{~mm}$.

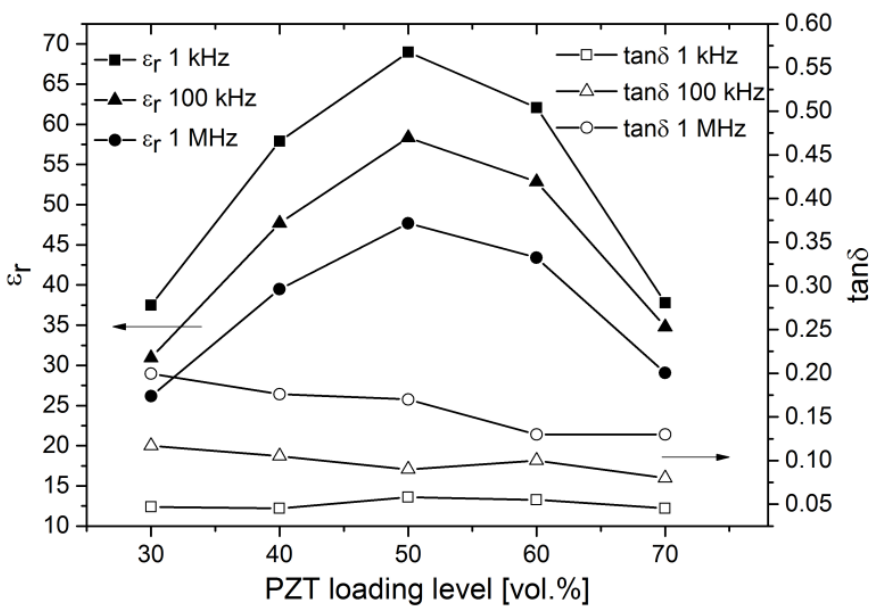

Figure 6. Dielectric properties of the composite as a function of PZT loading level of the composite before poling from $1 \mathrm{kHz}$ to $1 \mathrm{MHz}$.
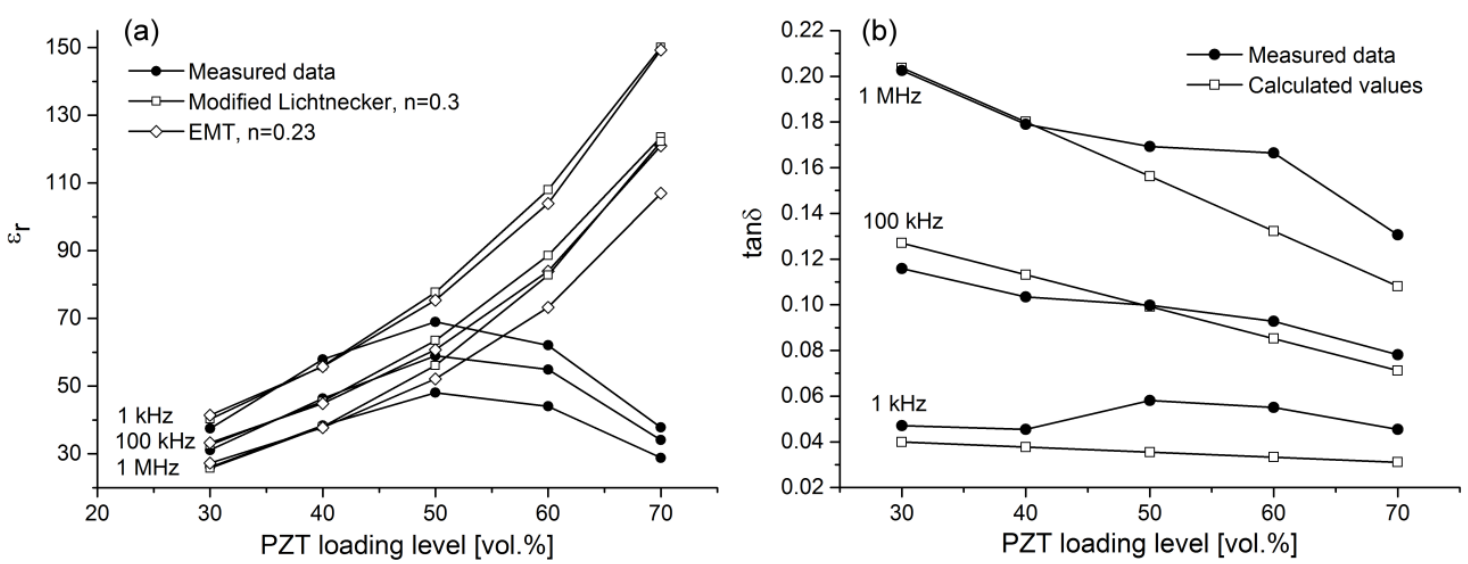

Figure 7. The calculated and measured permittivity (a) and loss tangent (b) as a function of PZT loading level of the composite. 


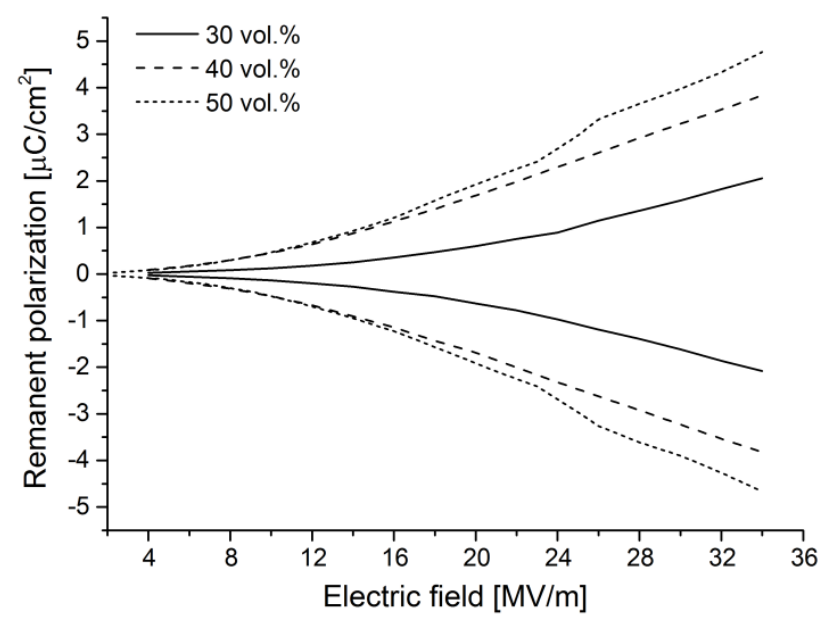

Figure 8. Remanent polarization as a function of electric field and PZT loading level of the composite.

\section{Tables}

Table 1.

Measured dielectric properties of bulk PZT and PVDF-TrFE before poling at room temperature.

\begin{tabular}{|c|c|c|c|c|c|c|}
\hline \multirow{2}{*}{ Bulk material } & \multicolumn{2}{|c|}{ @ $1 \mathrm{kHz}$} & \multicolumn{2}{|c|}{ @ 100 kHz } & \multicolumn{2}{|c|}{ @ $1 \mathrm{MHz}$} \\
\hline & $\varepsilon_{\mathrm{r}}$ & $\tan \delta$ & $\varepsilon_{\mathrm{r}}$ & $\tan \delta$ & $\varepsilon_{\mathrm{r}}$ & $\tan \delta$ \\
\hline PVDF-TrFE $_{56: 44}$ & 15 & 0.047 & 12 & 0.17 & 8 & 0.28 \\
\hline PZ29 & 1650 & 0.024 & 1500 & 0.029 & 1440 & 0.035 \\
\hline
\end{tabular}

Table 2.

Dielectric properties and piezoelectric coefficient $\left(\mathrm{d}_{31}\right)$ after poling at $15 \mathrm{MV} / \mathrm{m}$ at room temperature for $1 \mathrm{~h}$.

\begin{tabular}{|c|c|c|c|c|c|c|c|c|c|c|}
\hline \multirow{2}{*}{$\begin{array}{l}\text { Vol. \% } \\
\text { PZT in } \\
\text { the ink }\end{array}$} & \multicolumn{3}{|c|}{ @ $1 \mathrm{kHz}$} & \multicolumn{3}{|c|}{ @ 100 kHz } & \multicolumn{3}{|c|}{ @ $1 \mathrm{MHz}$} & \multirow[b]{2}{*}{$\underset{(\mathrm{pm} / \mathrm{V})}{\left|\mathrm{d}_{31}\right|}$} \\
\hline & $\varepsilon_{\mathrm{r}}$ & $\begin{array}{l}\Delta \varepsilon_{\mathrm{r}} \\
(\%)\end{array}$ & $\tan \delta$ & $\varepsilon_{\mathrm{r}}$ & $\begin{array}{l}\Delta \varepsilon_{\mathrm{r}} \\
(\%)\end{array}$ & $\tan \delta$ & $\varepsilon_{\mathrm{r}}$ & $\Delta \varepsilon_{\mathrm{r}}(\%)$ & $\tan \delta$ & \\
\hline 30 & 33 & -13 & 0.05 & 28 & -9.6 & 0.1 & 23 & -11.5 & 0.17 & 4.3 \\
\hline 40 & 44 & -7 & 0.03 & 40 & -13.7 & 0.08 & 34 & -11.5 & 0.09 & 8.8 \\
\hline 50 & 48 & -30 & 0.03 & 44 & -25.3 & 0.08 & 36 & -25.0 & 0.15 & 17.0 \\
\hline
\end{tabular}

